\title{
Numerical Simulation of ARCTIC Sea-ICE AND OCEAn Circulation
}

\author{
By David M. Holland
}

$\mathrm{C}$ URRENTLY THERE Is considerable interest in improving our understanding of the interactions between the components of the earth's climate system. The polar regions, which form an integral yet distinct part of this system, are believed to be particularly sensitive to anthropogenically induced global warming and therefore are worthy of special study. The polar climate subsystem consists of the atmosphere, the oceans, and the sea ice. The presence of sea ice on the ocean surface drastically alters the interaction between the atmosphere and the ocean at high latitudes.

Our understanding of the interactions in the polar regions has been hampered by a shortage of basin-wide observations due to the harsh climate. Those that do exist up to the late 1980s are reviewed by Carmack (1990). Numerical modeling thus provides an important tool for investigating the complex mechanisms and interactions that control polar climate. The northern and southern polar regions are very different from one another. The Arctic consists of an ocean surrounded by continental land masses, whereas the Antarctic has a continent surrounded by a high-latitude ocean. This study focuses on a numerical simulation of the Arctic using the recently developed Oberhuber (1993) ocean model.

The Arctic Ocean is essentially contained within a closed basin. It has the largest continental shelves in the world oceans. These shallow and broad margins cover about one-third of the surface area of the Arctic Ocean. The basin is divided into two subbasins, namely the Canadian Basin and the Eurasian Basin. These basins are sepa-

D.M. Holland, Department of Atmospheric and Oceanic Sciences and Center for Climate and Global Change Research, 805 Sherbrooke Street West, McGill University, Montreal, Quebec, Canada H3A 2K6; Ph.D. 1993, McGill University (supervisor: Lawrence A. Mysak). rated by the Lomonosov Ridge, which extends from Siberia across the Arctic Ocean to Greenland. The waters of the basin communicate with the Pacific Ocean through the narrow and shallow Bering Strait and with the Atlantic Ocean via the relatively wider and deeper Fram Strait as well as the wide opening between Spitsbergen and Norway. There is also a flow from the western Arctic through the Canadian Arctic Archipelago into Baffin Bay. Freshwater is received along the periphery of the basin from numerous rivers.

The Arctic Ocean is well stratified because of the annual cycle of sea-ice growth and melt and also because of river input. There is a strong pycnocline at $\sim 300 \mathrm{~m}$ depth, which separates the cold, fresh surface waters from the relatively warm, salty deeper waters. The general circulation of the waters within this basin is not well known. It is assumed that the surface mixed layer is dragged along by the moving ice surface and thus follows an anticyclonic path in the Canadian basin and then exits the basin through Fram Strait. The deeper waters are thought to flow in the opposite (i.e., cyclonic) sense. The deeper waters may be strongly constrained by topography and thus flow along the contours of bottom topography.

The present modeling work was motivated in part by two previous modeling studies of the Arctic Ocean, namely those of Hibler and Bryan (1987) and Semtner (1987). Both of these studies used a coupled sea-ice-ocean model with specified atmospheric forcing to simulate the general circulation of the Arctic sea-ice and ocean. Hibler and Bryan were not able to investigate the deeper circulation because they had imposed an artificial damping of the salinity and temperature fields back to long-term averages (i.e., a relaxation constraint) at all depths below the top level of their ocean model. Semtner
(1987) removed the relaxation constraint of Hibler and Bryan and simulated an anticyclonic circulation at all depths in the Canadian Basin while obtaining a cyclonic flow below $200 \mathrm{~m}$ depth in the Eurasian Basin. This anticyclonic flow pattern in the Canadian Basin is inconsistent with observations that suggest a cyclonic flow in that basin.

The Oberhuber model used here is a general circulation model based on the following ideas: isopycnals are used as Lagrangian vertical coordinates, a realistic equation of state is included, the primitive equations together with the hydrostatic approximation are applied, and a surface mixed layer and a snow and sea-ice model are coupled to the interior ocean. The sea-ice model incorporates both thermodynamics and dynamics. A fundamental difference from other sea-ice models is that Oberhuber uses a different numerical scheme (i.e., implicit) and also solves the sea-ice equations written in spherical coordinates. The work presented here is the first application of the Oberhuber model to the Arctic Ocean; Oberhuber (1993) has previously applied the model to the North Atlantic.

The so-called Atlantic layer of the Arctic Ocean is the result of warm, saline water penetrating into the Arctic Ocean via the Fram Strait (and also partly from the Barents Sea). This water is heavier than the surface Arctic waters and subducts as it travels north of Fram Strait, occupying the water column between 300 and $1,000 \mathrm{~m}$ below the surface. The model simulation of the velocities and temperatures at a depth of $500 \mathrm{~m}$ are shown in Figure 1 . The velocity pattern indicates that the waters there are basically constrained to follow the topography. The modeled circulation consists of three principal cyclonic gyres (see the numbers 1, 2, and 3 in Fig. 1), which simply mimic the pattern of the ocean 
topography. This circulation can be compared with the circulation inferred from earlier temperature and salinity measurements, which show a single basin-wide gyre as opposed to the multigyre structure shown here. However, an analysis of recent data collected during the 1991 Oden cruise suggests the existence of a multigyre structure (Rudels et al., 1993).

The modeled temperature shows a pattern consistent with the circulation. It shows the warm, saline Atlantic water entering via Fram Strait. The temperature decreases as the water circulates cyclonically in the Eurasian Basin. This cooling of the Atlantic layer water is due to mixing and diffusion of the Atlantic layer water with the waters above and below it. Similarly, the temperature pattern suggests a cyclonic circulation in the Canadian Basin. The Atlantic layer water enters the Canadian Basin by flowing over
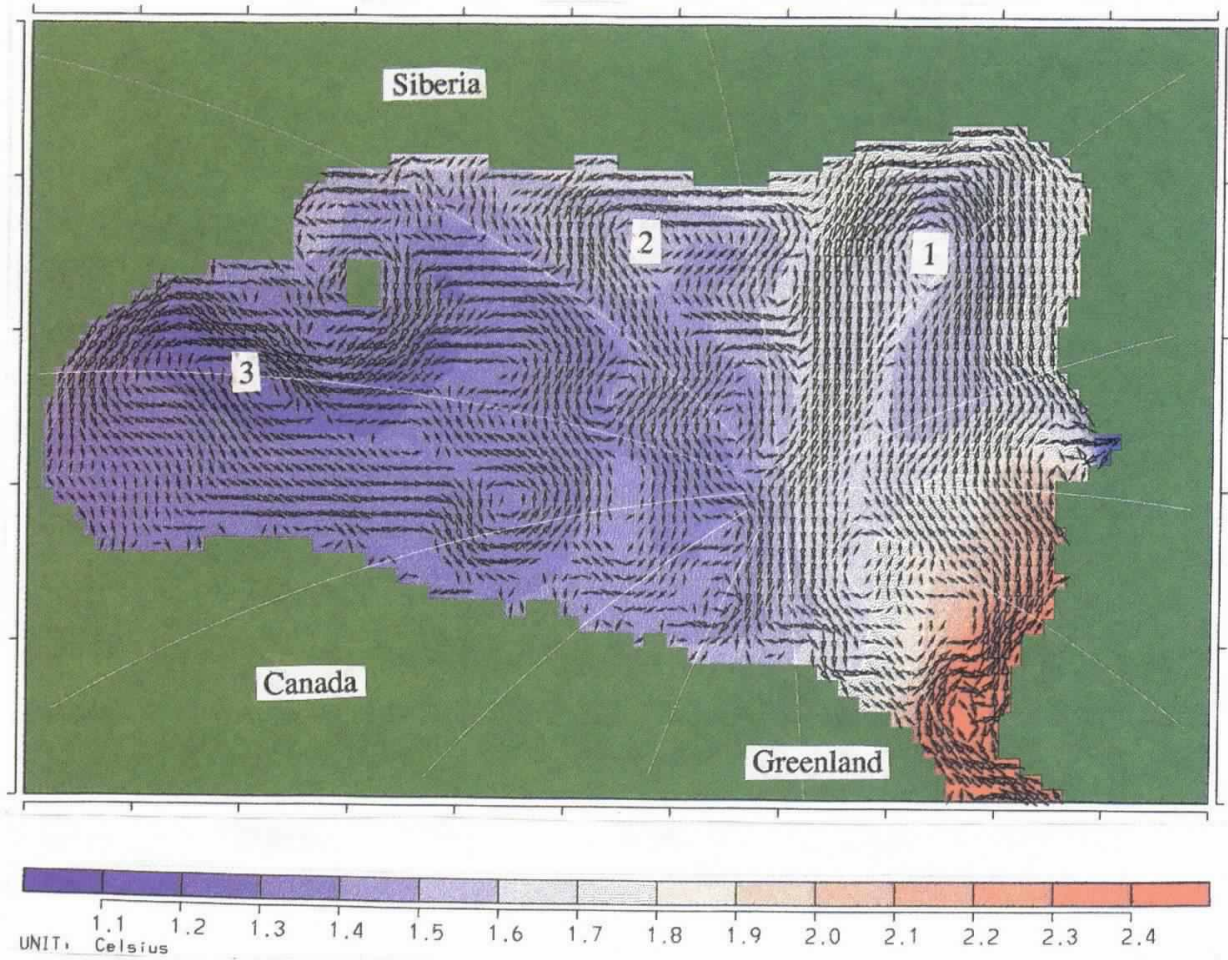

Fig. 1: Simulated temperature and circulation of the Atlantic layer (i.e., depth of 500 $m$ ) in the Arctic Ocean (for January). The underlying contours give the temperature field, which ranges from hot temperatures in excess of $2.4^{\circ} \mathrm{C}$ in Fram Strait to cold temperatures less than $1^{\circ} \mathrm{C}$ in the center of the Canadian Basin. The overlying vectors illustrate a multigyre cyclonic circulation with maximum speeds of $\sim 3 \mathrm{~cm} / \mathrm{s}$. The solid green color indicates land. The thin white lines represent lines of constant longitude spanning out from the North Pole, which is located near the center of the image. The numbers 1, 2, and 3 in the figure show the centers of three cyclonic gyres. tions in the global thermohaline circulation could have impacts on the Arctic Ocean and vice versa. Secondly, a major limitation of the model is that it consists only of a coupled ice-ocean model with the atmosphere specified. In reality, the polar climate system includes three freely interacting systems, namely the atmosphere, sea-ice, and ocean, with various feedback processes. Only the sea-ice and ocean are coupled together here; consequently, there are no feedbacks operating between the atmosphere and the sea-ice or ocean.

The results of this work, which are further described in Holland (1993), indicate that further studies of the polar regions can be profitably carried out using the Oberhuber model. Future work will involve studying interannual variability of the Arctic sea-ice cover and simulating the general circulation of the Arctic Ocean and its connection to the global circulation. The model will likewise be used to investigate the circulation in the Antarctic to make comparisons with observations and other modeling studies.

\section{Acknowledgments}

This project was carried out with the assistance of Prof. Lawrence A. Mysak and Dr. Josef M. Oberhuber. Computing resources were provided by Cray Research Inc. and the Arctic Region Supercomputing Center of the University of Alaska.

\section{References}

Carmack, E.C., 1990: Large-scale physical oceanography of polar oceans. In: Polar Oceanography, Part A, Physical Science, W.O. Smith, ed. Academic Press, New York, 171-222.

Hibler, W.D. III and K. Bryan, 1987: A diagnostic ice-ocean model. J. Phys. Oceanogr., 17, 987-1015.

Holland, D.M., 1993: Numerical simulation of the Arctic sea ice and ocean circulation. Ph.D. thesis, McGill University, 203 pp.

Oberhuber, J.M., 1993: Simulation of the Atlantic circulation with a coupled sea ice-mixed layer-isopycnal general circulation model. Part I: model description. J. Phys. Oceanogr., 23, 808-829.

Rudels, B., E.P. Jones, L.G. Anderson, and G. Kattner, 1994: On the origin and circulation of the Atlantic Layer and the intermediate depth waters of the Arctic Ocean. In: The Role of the Polar Oceans in Shaping the Global Environment, R. Muench and O.M. Johannesen, eds. Amer. Geophys. Union, Washington D.C. In Press.

Semtner, A.J., Jr., 1987: A numerical study of sea ice and ocean circulation in the Arctic. $J$. Phys. Oceanogr.. 17, 1077-1099. $\square$ 